\title{
EDITORIAL
}

\section{MOBILIDADES, IMOBILIDADES E MOBILIZAÇÕES EM TEMPOS DE COVID-19}

\author{
Mobility, Immobility and Mobilizations in Times of Covid-19
}

\author{
Roberto Marinucci*
}

\begin{abstract}
A guerra dos Estados-nações contra os migrantes, essa lógica imunológica de exclusão, aparece hoje em toda a sua ridícula crueldade. Nada nos preservou do coronavírus, nem mesmo os muros patrióticos, as fronteiras arrogantes e violentas dos soberanistas. A pandemia global mostra a impossibilidade de se salvar - a não ser com ajuda mútua ${ }^{1}$. (Donatella Di Cesare, 2020)
\end{abstract}

A pandemia de Covid-19 tem alimentado reflexões e debates sobre prioridades e fundamentos de nossas sociedades, expondo conflitos e contradições. O "fim da história", anunciado hieraticamente por Fukuyama no fim do século passado, assume hoje conotações bem diferentes, quase que paradoxais: o planeta terra será ainda habitável para a humanidade? O capitalismo neoliberal, após décadas de desmantelamento de serviços sociais, é a solução ou o problema (Chomsky, 2020; Balibar, 2020)? Sociedades atadas a um obsessivo presente, de repente se interrogam sobre o futuro e perscrutam o passado em busca de alguma luz.

No interior desse amplo e complexo debate se desenrola também uma reflexão mais peculiar sobre a pandemia de Covid-19 e a mobilidade humana, que é tema do Dossiê do número 61 da REMHU, Revista Interdisciplinar da Mobilidade Humana. Trata-se de uma reflexão que não diz respeito apenas a um grupo específico de seres humanos - as assim chamadas pessoas migrantes e refugiadas -,

Editor-chefe da Revista REMHU, Centro Scalabriniano de Estudos Migratórios (CSEM). Brasília DF, Brasil. E-mail: remhu@csem.org.br. Orcid: https://orcid.org/0000-0002-2042-2628.

1 "La guerra degli Stati nazionali contro i migranti, quella logica immunitaria dell'esclusione, appare oggi in tutta la sua ridicola crudezza. Nulla ci ha preservato dal coronavirus, neppure i muri patriottici, le frontiere boriose e violente dei sovranisti. La pandemia globale mostra l'impossibilità di salvarsi - se non con l'aiuto reciproco" (Donatella Di Cesare, 2020). 
mas, a partir deste, aprofunda os princípios axiológicos que permeiam e movem as sociedades contemporâneas em todos os seus aspectos.

1. A primeira vertente dessa reflexão versa sobre a negação ou violação de direitos de pessoas migrantes. Parte-se da constatação de que a profilaxia hegemônica para contrastar o coronavírus - distanciamento e isolamento social - não afetou todos os grupos sociais da mesma maneira. No âmbito do trabalho/ economia, pessoas migrantes e refugiadas foram particularmente afetadas em decorrência da informalidade e da precarização dos empregos, das limitações das redes sociais de apoio, da dificuldade de acesso a ajudas emergenciais (sobretudo entre os que se encontram em situação administrativamente irregular) e, por vezes, pela necessidade de enviar remessas. Houve também uma maior exposição à pandemia, devido, com frequência, às condições de moradia, ao uso de meios coletivos de transportes, ao limitado acesso aos sistemas sanitários (e às vacinas) e, especialmente, à necessidade de continuar circulando e trabalhando, inclusive pelo frequente envolvimento em atividades consideradas essenciais.

De forma específica, merece um destaque a situação de muitas mulheres migrantes, particularmente vulnerabilizadas por trabalharem nas áreas da saúde e do cuidado, pelo aumento da violência doméstica e pela redução de serviços de apoio. Como nos alerta Balibar (2020), de fato, discriminações conjunturais se somaram às discriminações estruturais.

Sobre essa abordagem cabe destacar dois artigos do dossiê da REMHU. Primeiramente, Luís Felipe Aires Magalhães, Lúcia Bógus e Rosana Baeninger apresentam alguns resultados quantitativos da pesquisa "Impactos da Pandemia de Covid nas Migrações Internacionais" (PUC-MG, UNICAMP), com destaque para a questão do trabalho. O artigo, focado no Estado de São Paulo, no Brasil, analisa, antes de tudo, o padrão de disseminação da pandemia e detecta os percursos de difusão no interior da capital paulista e o sucessivo processo de interiorização. Nesta ótica cabe destacar o fator geográfico (os eixos rodoviários de mobilidade) e aquele socioespacial ("diferenciais de renda, de escolaridade, de ocupação, de acesso aos serviços de saúde e de bem-estar urbano"). Em termos gerais, a pandemia evidenciou, segundo os autores, a presença de uma "fronteira sociológica (...) invisível, mas muito objetiva, que rompe o tecido social urbano, produz invisibilidades e alteridades e reduz ao limite do compreensível a empatia com o outro".

Já Salvatore Palidda desenvolve uma abordagem interpretativa do fenômeno migratório contemporâneo enquanto passagem de um paradigma biopolítico (deixar viver) para um paradigma tanatopolítico (deixar morrer). O autor sustenta que o neoliberalismo globalizado, unido ao medo das possíveis consequências do crescimento demográfico, está levando a um novo paradigma que não visa mais ao uso instrumental da imigração - deixar viver para explorar - mas, com sempre maior frequência, à eliminação da população em excesso, das vidas descartáveis. 
A pandemia fortalece essa tendência, inclusive mediante o fechamento das fronteiras, a interrupção da acolhida de solicitantes de refúgio e a proibição da ajuda humanitária por parte das ONGs.

2. A segunda vertente de reflexão sinaliza como o combate à pandemia foi travado prioritariamente através de limitações da mobilidade e, consequentemente, das próprias migrações (Ruseishvili, 2020). As restrições das migrações, na realidade, não representam uma novidade. A fobia do migrante estrangeiro vetor de uma doença estrangeira (2020) se adiciona às anteriores fobias focadas no terrorismo (2001), na crise financeira (2008) e na suposta invasão de refugiados no Mediterrâneo (2015) ou de caravanas na fronteira norte do México (2018). A impressão é que a pandemia se tornou um ulterior argumento para legitimar políticas de securitização na ótica do Estado de exceção (Agamben, 2004) já implementadas há algumas décadas. Trata-se, no fundo, de políticas de imunização contra a alteridade (Esposito, 2005), a saber, contra aquelas pessoas que por alguma razão são consideradas e/ou tratadas como "impuras" ou "contaminadas" pelo país de nascimento, pela cor da pele, pelo fenótipo, pela nacionalidade dos pais ou, mais simplesmente, pelo sotaque. Muros e outras barreiras, materiais e imateriais, são erguidos para imunizar as populações nacionais contra o vírus estrangeiro e dos estrangeiros (da estrangeiridade).

As limitações das migrações são evidentes: fechamentos de fronteiras, detenções, deportações, inadmissões, lentidões ou interrupções dos trâmites burocráticos dos pedidos de refúgio. No entanto, prejudicada foi também a mobilidade, em várias vertentes, como a circularidade migratória - tornou-se extremamente difícil contar com estratégias por assim dizer "pendulares" de deslocamento -, a mobilidade secundária - muitos migrantes conseguem ainda entrar na União Europeia (mobilidade primária), mas os deslocamentos internos são quase impossíveis - e, inclusive, o retorno para a própria terra - emblemáticos os casos de venezuelanos/as na América Latina e de numerosos migrantes internos da Índia após o repentino lockdown. É evidente que o bloqueio de migrações e mobilidades afetou também a fuga em busca de refúgio, com todas suas consequências.

Pelo menos dois artigos do dossiê priorizam esse enfoque. Lorena Mena Iturralde e Rodolfo Cruz Piñeiro abordam a imobilidade e a desproteção de pessoas migrantes e refugiadas em contexto pandêmico na fronteira norte do México. O foco do artigo está no "atrapamiento", entendido como "estancamiento [de migrantes] en zonas precarias y provisionales de asentamiento, debido a sus necesidades de asistencia social, a una condición migratoria irregular cada vez más prolongada en México y a la inseguridad de los contextos de espera". Conforme os autores, o atrapamiento sanitário se acrescenta aos atrapamientos geográficos dos muros - e legislativos - das políticas e burocracias migratórias - que impõem imobilidades forçadas. 
As dinâmicas migratórias na fronteira ítalo-francesa no período do primeiro lockdown são aprofundadas por Luca Giliberti e Davide Filippi. Os autores evidenciam as mudanças provocadas tanto pela pandemia quanto por suas políticas de gerenciamento e os efeitos cumulativos em relação à governança migratória pré-pandêmica. A necessidade de isolamento e distanciamento social tem causado também a redução da ação solidária, gerando, em alguns casos, sugestivos espaços de autonomia e autogestão por parte das pessoas em trânsito. Trata-se de uma situação que "permette una riflessione critica nelle reti solidali e diventa un'opportunità per nuovi modelli nel prossimo futuro".

Merece ser citado aqui também o "Relato" de Diane Portugueis sobre sorveteiros ítalo-brasileiros. A autora reflete sobre o caso de Flavinho que, no contexto da pandemia, é impedido de viajar do Brasil para a Alemanha a trabalho, apesar de possuir "todos os documentos, comprovantes, trabalho certo, moradia", tendo inclusive o passaporte italiano. A imobilidade imposta pela pandemia, segundo a autora, exige a construção de novas estratégias de mobilidade mesmo para aqueles "tão acostumados ao ir e vir permanente, irrestrito".

3. Aqui se insere uma terceira abordagem que merece destaque: num contexto de acirramento de violações de direitos e de restrições à mobilidade, vários estudos e reflexões focam a agency dos sujeitos migrantes, suas trajetórias de luta, resiliência e enfrentamento das velhas e novas adversidades. Trata-se, por vezes, de atos políticos - individuais ou coletivos - em que pessoas "abjetas" assumem sua condição de sujeitos cidadãos. Pelo menos cinco artigos do dossiê da REMHU priorizam esta abordagem.

Ana López-Sala analisa o surgimento e o desenvolvimento de uma mobilização social na Espanha em busca da regularização de migrantes sinpapeles. Pessoas migrantes, no contexto da pandemia, resolveram encabeçar um movimento reivindicativo "para dar respuesta política a la situación de miles de personas inmigrantes irregulares que se emplean en la economía sumergida". O movimento \#RegularizaciónYa, que a autora interpreta na ótica da "ciudadanía performativa" de Engin Isin, apesar de não ter alcançado seus objetivos específicos, evidenciou a capacidade ativa de mobilização de indivíduos e grupos migrantes que, com o apoio de parte da sociedade civil, reivindica um espaço de cidadania.

Passando da Espanha para a Argentina, Natalia Gavazzo e Lucila Nejamkis focam as estratégias de enfrentamento da pandemia por parte de mulheres migrantes na Grande Buenos Aires. As autoras utilizam o paradigma da interseccionalidade e lançam mão da categoria analítica do "cuidado comunitario" para descrever e analisar a formação de redes de cidadãos - lideradas principalmente por mulheres - em contextos marcados por uma carente presença do Estado e pela emergência sanitária. Conforme as autoras, "la condición de 'ser migrante', 'ser mujer' y 'ser pobre' son pertenencias que en su simultaneidad multiplican la vulnerabilidad de las personas y que los obligan a desplegar estrategias de organización para garantizar 
la reproducción de la vida, tanto a nivel de las familias como de las asociaciones comunitarias".

Às vezes, algumas "redes" são formadas espontânea e temporariamente por grupos heterogêneos que possuem objetivos imediatos comuns. A partir dessa perspectiva, Mauricio Palma-Gutierrez analisa um episódio de resistência por parte de um grupo de migrantes venezuelanos acampados em Bogotá na tentativa de regressar à terra de origem. No contexto marcado pela imobilidade imposta pela pandemia e pelas tentativas das autoridades públicas colombianas de disciplinar o movimento, o autor focaliza o ato de "acampar" (to camp) enquanto ato público e político mediante o qual uma coalizão heterogênea e temporária de pessoas migrantes converte uma situação de vulnerabilidade em uma ferramenta para produzir uma transformação social.

Finalmente, focando a realidade brasileira, Nathália Antonucci narra as estratégias subjetivas de enfrentamento da pandemia por parte de uma solicitante de refúgio lésbica venezuelana, residente no Brasil, em termos relacionais (a separação das filhas), espaciais (as (i)mobilidades) e existenciais (as lutas pela inclusão biológica e social). O artigo atenta para a diversificação dos sujeitos envolvidos na crise sanitária e questiona aquelas abordagens homogeneizadoras que camuflam "marcadores sociais, tais como classe, gênero, raça, nacionalidade, sexualidade, [que] ao longo da história, determinaram uma espécie de 'cordão sanitário social' entre seres humanos".

Esses quatro textos ressaltam como as vulnerabilidades decorrentes da condição migratória e outros marcadores sociais, em contexto pandêmico, com frequência não inibem a agency das pessoas migrantes/refugiadas e suas potencialidades de responder a desafios em diferentes níveis: institucional, visando mudanças políticas e legislativas; comunitário, visando o fortalecimento de redes de apoio ou o conseguimento de objetivos comuns; e familiar/individual, visando à manutenção de relacionamentos e à sobrevivência biológico/social.

Cabe citar nesta abordagem também o artigo de Renan Vidal Mina e Oswaldo Truzzi. Em épocas de crise é sempre importante um olhar retrospectivo. Experiências do passado podem iluminar o presente e pavimentar o futuro. A anamnese deve tomar o lugar das amnésias. É nessa ótica que os autores propõem uma releitura sociológica do surto de febre amarela ocorrido em Campinas, Brasil, no contexto da imigração italiana urbana do final do século XIX. O artigo descreve e analisa as estratégias de enfrentamento da crise sanitária por parte de integrantes do Circolo Italiani Uniti, sua relação com o processo de integração na sociedade campinense e, inclusive, de formação de uma identidade italiana comum. Entre outros aspectos, a análise sociológica aponta para a "importância da promoção de uma agenda social que de fato contemple as populações imigrantes".

4. Finalmente, há um último foco de reflexão, que perpassa de diferentes maneiras todos os textos do dossiê. Já foi amplamente demonstrado que o 
coronavírus não é tão "democrático" como inicialmente anunciado, pois afeta de forma muito diferente os vários segmentos sociais. Mas algo mudou. Não se pode negar que aqueles "muros" construídos nas fronteiras para "conter" a mobilidade de pessoas migrantes e refugiadas, agora são erguidos nas portas das casas - e, por vezes, dos quartos - de toda a população residente. O risco de vida, a imobilidade imposta e a forte insegurança em relação ao futuro agora são experiências vivenciadas por grande parte da população mundial. De alguma forma todos/as compartilhamos algo da condição das pessoas migrantes e refugiadas. Será que isso trará uma maior consciência planetária e cosmopolita (Balibar, 2020)?

Ademais, cabe lembrar que todos os países do mundo, de fato, implementaram algum tipo de lockdown para amenizar os impactos sociais da pandemia, com graves consequências em nível econômico. Uma pergunta surge: como será possível, daqui para frente, rejeitar "mini-lockdowns" (no sentido econômico), objetivando a criação de corredores migratórios humanitários, garantir a acolhida de solicitantes de refúgio, promover a reconversão ecológica dos parcos industriais (Agostinelli, 2020) ou erradicar a fome no mundo? O rei está nu. Estamos diante de uma bifurcação: continuar com os paradigmas imunitários, vacinando as populações contra os "bárbaros" mediante muros, populismos e fake news, ou assumir a comum dignidade de todos/as os moradores do planeta terra, a fraternidade universal da qual nos fala Papa Francisco, a laica fraternité. Não nos salvaremos sozinhos.

$$
\text { **** }
$$

Na Seção "Artigos" da REMHU 61, Sandro Martins de Almeida Santos e Ivón José Lo Bianco Meza abordam o tema do projeto migratório de uma família nuclear venezuelana urbana heteronormativa no Brasil. A narração da trajetória é o ponto de partida para a análise de uma tipologia de migração familiar, com destaque para aspectos como: os processos de negociação, as controvérsias, bem como os laços duradouros de afetividade e lealdade.

Roberto Pessoa de Queiroz Falcão, Eduardo Picanço Cruz e Ricardo Ferraz Raats apresentam os resultados de uma pesquisa junto a brasileiros residentes na Estônia. Os autores refletem sobre a incipiente formação de uma diáspora, analisando indicadores como: fatores de atração e expulsão, trajetórias, incorporação no país do leste europeu e perspectivas migratórias.

Selene Gaspar Olvera e Rodolfo García Zamora estudam a situação de mexicanos que ingressaram na infância nos EUA. Os autores analisam as características sociolaborais e evidenciam os fatores que mais impactam nos processos de integração e de inserção no mercado de trabalho, a saber, a idade de chegada e a regularização migratória.

Finalmente, Ulises Alberto Rincón Zárate aborda a relação entre sujeito migrante, território e alteridade. A partir de uma abordagem sócio-fenomenológica, 
o autor reflete sobre o processo de apropriação e ressignificação de novos territórios enquanto elemento relevante nas dinâmicas identitárias de integração.

A resenha de Andrea Pacheco Pacifico e Sarah Fernanda Lemos Silva sobre o livro Estrangeiro, nunca mais! Migrante como sujeito de direito e a importância do advocacy pela nova lei de migração brasileira de Ebenézer Marcelo Marques de Oliveira e Cyntia Sampaio encerra o número da revista.

Desejamos a todas e todos uma boa leitura.

\section{Referências bibliográficas}

AGAMBEN, Giorgio. Estado de exceção. São Paulo: Boitempo, 2004.

AGOSTINELLI, Mario. Coronavirus e emergenza climatica. Roma: Castelvecchi, 2020. BALIBAR, Étienne. Al cuore della crisi. Roma: Castelvecchi, 2020.

CHOMSKY, Noam. Crisi di civiltà. Pandemia e capitalismo. Milano: Salani, 2020.

DI CESARE, Donatella. Virus sovrano? L'asfissia capitalistica. Torino: Bollati Boringhieri, 2020.

ESPOSITO, Roberto. Immunitas. Protección y negación de la vida. Buenos Aires: Amorrortu, 2005.

RUSEISHVILI, Svetlana. Quatro lições da pandemia sobre a mobilidade no mundo contemporâneo. Sociologia na Pandemia \#5, 2020. Disponível em: < http://www. ppgs.ufscar.br/sociologia-na-pandemia-5/>. Acesso em: 07.04.2021. 